\section{Frank elevation of bronchoalveolar lavage fluid IgE level in hyperimmunoglobulin E syndrome}

\author{
Alan Altraja \\ Department of Pulmonary Medicine, \\ University of Tartu, Estonia
}

\section{Abstract}

Hyperimmunoglobulin E syndrome (HIES) is a rare hereditary immunodeficiency disorder characterized mainly by an elevated serum immunoglobulin E ( $\operatorname{IgE}$ ) level. However, the IgE level in bronchoalveolar lavage fluid (BALF) of HIES patients has not been addressed before. The case of a 24 -year-old non-smoking Caucasian male HIES patient with classical skin infections in childhood and recurrent staphylococcal pneumonias is reported. Out of an infectious episode, the total IgE level was measured in BALF by chemiluminescence method, along with appropriate analysis of immunoglobulins A (IgA), G (IgG) and $\mathrm{M}$ (IgM), albumin and cellular components. In parallel, the respective markers were measured in serum. An elevated level of BALF IgE of $15.10 \mathrm{ng} / \mathrm{mL}(6.24 \mathrm{IU} / \mathrm{mL})$ along with the marked heightening of IgE in serum at 130,583 $\mathrm{ng} / \mathrm{mL}(53,960 \mathrm{IU} / \mathrm{mL})$ was observed. The relative coefficients of excretion (RCE), based on BALF and serum albumin concentrations (100.6 mg/L and $39 \mathrm{~g} / \mathrm{L}$, respectively), were $0.0448,1.49,1.94$ and $<3.40$ for IgE, IgA, IgG and IgM, respectively. The results show a frank increase in BALF IgE level in HIES compared to that reported for healthy individuals and the low RCE value for IgE suggest a diffusion of IgE across the respiratory membrane. This case study demonstrates a markedly elevated BALF IgE level in HIES that could be used to support the diagnosis, but also raises important BALFrelated aspects in HIES that provoke further studies on BALF from HIES patients.

\section{Introduction}

Hyperimmunoglobulin E syndrome (HIES) is a rare hereditary immunodeficiency disorder characterized by an elevated serum level of immunoglobulin E (IgE), peripheral eosinophilia and recurrent severe skin and sinopulmonary infections caused mostly by Staphylococcus aureus. ${ }^{1}$ Apart from the knowledge of markedly elevated serum IgE level and usually normal levels of other immunoglobulins in HIES, ${ }^{2}$ determining the level of IgE in bronchoalveolar lavage fluid (BALF) of HIES patients has not been in focus before.

\section{Case Report}

A 24-year-old presented-smoking Caucasian male HIES patient with classical eczematoid rashes and recurrent pustular skin infections of staphylococcal aetiology manifested since 3 months of age on his face, scalp and limbs. From the age of 5 , the patient had severe recurrent bilateral staphylococcal pneumonias, although milder respiratory tract infections such as purulent otitis media were reported already as early as 1.5 years of age. The patient also had other findings characteristic of HIES. ${ }^{1,3}$ These included slightly hyperextensible joints, clubbed fingers and characteristic facial appearance with exaggerated skin pores, but no significant scoliosis, bone fractures from minimal trauma, or abnormalities associated with primary teeth. His National Institutes of Health (NIH) HIES score was 57. There has been no HIES cases diagnosed in his family. The patient has received continuous prophylactic treatment with trimethoprim/sulfamethoxazole and has experienced infection-free periods of up to 5 years until a severe cavitating pneumonia occurred 6 months prior to the current study. Continuous cefuroxime axetil therapy followed afterwards and at presentation, the patient was free of complaints and clinical or laboratory signs of an active infection. Nevertheless, he had radiographically visible pneumatoceles (Figure 1A, 1B) and sequelae of pneumonias in the form of multiple scarring, slightly reduced lung volumes (forced vital capacity, FVC and forced expiratory volume in one second, FEV1 $71 \%$ and $68 \%$, respectively) and a decline in diffusion capacity of the lung $\left(\mathrm{D}_{\mathrm{L}} \mathrm{C} 0,66 \%\right.$ predicted). No mutations in the signal transducer and activator of transcription 3 (STAT3) gene were detected in this patient. After obtaining informed consent, fiberoptic bronchoscopy was performed out of clinical exacerbation to check for signs of infection and bacterial aetiology and to assess disease markers in BALF (Figure 1C). Bronchoalveolar lavage was performed by instilling a total of $200 \mathrm{~mL}$ saline, divided into 20 -mL aliquots, into the $4^{\text {th }}$ segment in the right middle lobe, free of radiographically detectable opacities. The total IgE content was measured by chemiluminescence immune method (CLIA) using an Immulite ${ }^{\circledR} 2000$ analyser (Siemens Medical Solutions Diagnostics, Los Angeles, CA, USA), whereas the levels of total IgA, total IgG and total IgM were assessed with the use of immunoturbidimetry. Measurement of the contents of IgA, IgG and $\operatorname{Ig} M$ required concentration of the BALF sample. The BALF cellular components
Correspondence: Alan Altraja, Department of Pulmonary Medicine, University of Tartu, 8 Puusepa Street, 51014 Tartu, Estonia.

Tel. +372.7.318.901 - Fax: +372.7.318.905 .

E-mail: alan@kliinikum.ee

Key words: bronhcoalveolar lavage, immunoglobulin E, hyperimmunoglobulin E syndrome, eosinophils, T-lymphocytes.

Acknowledgments: the author would thank Mr. Aivar Orav for the skillful assistance in performing analyses on BALF.

Received for publication: 4 January 2011.

Accepted for publication: 6 May 2011.

This work is licensed under a Creative Commons Attribution 3.0 License (by-nc 3.0).

(C) Copyright A. Altraja, 2011

Licensee PAGEPress, Italy

Chest Disease Reports 2011; 1:e4

doi:10.4081/cdr.2011.e4

were assessed using both cytospin preparations and sections of cell blocks created from the pellet of centrifuged BALF.

An aspirated fluid recovery of $80 \%(160 \mathrm{~mL})$ was obtained. No ciliated bronchial epithelial cells and no eosinophils were detectable in BALF displaying $95 \%$ alveolar macrophages. A very limited number of eosinophils (2 cells on average per low power field) were detected only when the sections of cell blocks created from the centrifuged BALF pellet was analysed. The proportions of neutrophils and lymphocytes in BALF were $1 \%$ and $4 \%$, respectively, with the CD4/CD8 T-lymphocyte ratio of 0.29 . Analysis revealed an elevated IgE level in BALF of $15.10 \mathrm{ng} / \mathrm{mL}(6.24 \mathrm{IU} / \mathrm{mL})$, whereas the levels of total IgA, total IgG and total IgM appeared at $9.0 \mathrm{mg} / \mathrm{L}, 110.0 \mathrm{mg} / \mathrm{L}$ and $<15 \mathrm{mg} / \mathrm{L}$, respectively. The level of IgE in serum was 130,583 $\mathrm{ng} / \mathrm{mL}(53,960 \mathrm{IU} / \mathrm{mL})$, while the serum levels of $\operatorname{IgA}$, IgG and $\operatorname{IgM}$ were $2.34 \mathrm{mg} / \mathrm{mL}, 22.0$ $\mathrm{mg} / \mathrm{mL}$ and $1.71 \mathrm{mg} / \mathrm{mL}$, respectively. To standardise the immunoglobulin levels, as well as to assess the possible transudation of the immunoglobulins, with use of BALF and serum albumin concentrations $(100.6 \mathrm{mg} / \mathrm{L}$ and 39 $\mathrm{g} / \mathrm{L}$, respectively), the relative coefficients of excretion (RCE) were calculated according to the formula $\mathrm{RCE}=\left(\left[\operatorname{Ig}_{\mathrm{BALF}}\right] /\left[\operatorname{Ig}_{\text {serum }}\right]\right) /$ $\left(\left[\right.\right.$ albumin $\left._{\text {BALF }}\right] /\left[\right.$ albumin $\left.\left._{\text {serum }}\right]\right){ }^{4}$ For IgE, IgA, IgG and IgM, the RCE values were $0.0448,1.49$, 1.94 and $<3.40$, respectively. The patient had peripheral eosinophilia of $1.10 \times 10^{9} / \mathrm{L}(23 \%$ of the total leukocyte count of $4.77 \times 10^{9} / \mathrm{L}$ ), normal lymphocyte count (33\%) and decreased neutrophil count (34\%). 


\section{Discussion}

The IgE level in the current patient with HIES should be deemed as frank heightening since it appeared at a concentration, which is usually detected in the serum from normal individuals and exceeds the range reported in the BALF of healthy individuals $(0.06-0.3)^{5}$ at least 50 -fold. As is the case in a healthy person, ${ }^{6}$ there is no evidence to suggest a local alveolar synthesis of IgE in HIES and therefore, the notified heightening of IgE in the BALF reflects rather the markedly increased serum IgE level. The possibility that the high BALF IgE level in HIES derives from diffusion across the respiratory membrane is further supported by the sufficiently low RCE value for IgE in this case study, compared to that of $>1$ for other immunoglobulins. Distinct from that in the

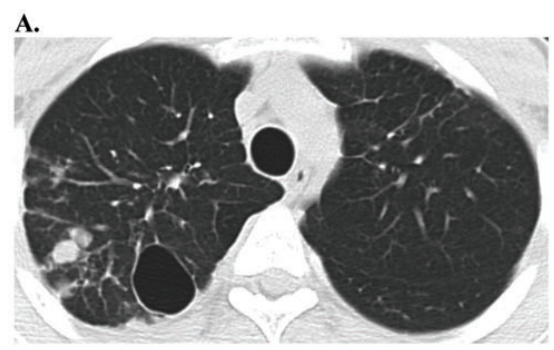

B.

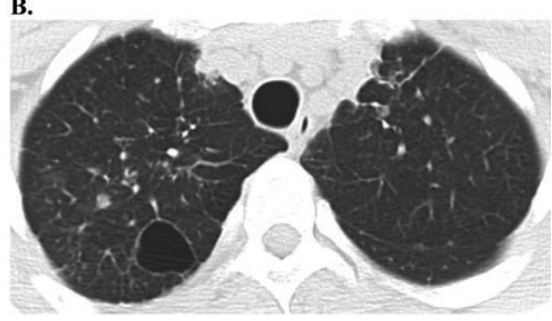

C.

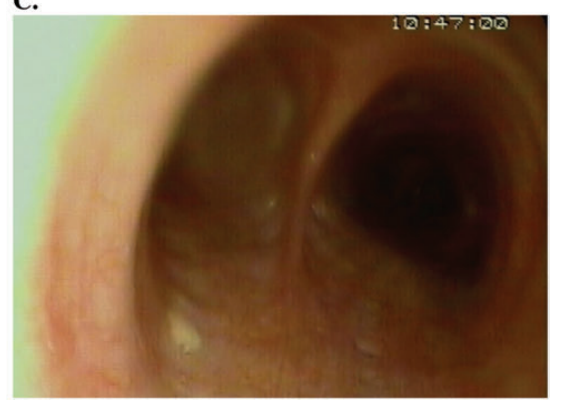

Figure 1. Images from a 24-year-old male patient with hyperimmunoglobulin $\mathrm{E}$ syndrome (HIES). (A) A chest computed tomography scan during a clinical exacerbation showing a thin-walled pneumatocele visible in the right upper lobe along with patchy consolidations characteristic of Staphylococcus aureus pneumonia. (B) A computed tomography scan depicting the same region during a clinical remission. (C) A bronchoscopic view of the main bronchi out of clinical exacerbation. case of IgE, the RCE >1 suggests that the levels of IgA, IgG and IgM in BALF do not simply result from diffusion but can more likely be derived from a local immune response. ${ }^{4}$ Indeed, compared to the values reported for healthy individuals, ${ }^{7,8}$ in this HIES patient, the IgA levels were normal in both BALF ${ }^{8}$ and serum, whereas those of IgG were elevated at least 5.4 fold in BALF $^{7}$ and slightly in serum. Elevated BALF IgE has also been reported in atopic asthmatics with a further increase in both total and allergen-specific IgE after segmental allergen challenge. ${ }^{9}$ However, the fact that asthmatics present with RCE values for the total IgE as high as 29.1 suggests a selective local generation of $\operatorname{IgE}$ antibodies within the lung, characteristic of pulmonary atopy, and, on the other hand, further supports the diffusion if IgE from circulation in HIES. The molecular mechanisms underlying the heightened serum IgE levels in HIES still remain unresolved..$^{10}$ However, recent studies $^{11,12}$ identified dominant-negative mutations in the STAT3 gene as a major molecular etiology of the specific immunodeficiency mechanisms in the classical or type 1 HIES. ${ }^{10}$ Rather than associated with primary neutrophil chemotactic defects, ${ }^{13}$ the pulmonary and cutaneous staphylococcal infections in HIES are most likely due to defects in differentiation of Th17 cells ${ }^{14-17}$ resulting in significantly decreased Th17 cell counts following mutations in the STAT3 gene. ${ }^{18,19}$ This leads to deficiency of Th17 cytokines and, as a result, the lack of neutrophil-recruiting chemokines and antimicrobial $\beta$-defensins crucial in protecting against Staphylococcus aureus, especially in the epithelial cells of the lung and skin. ${ }^{20}$ The decreased CD4/CD8 T-lymphocyte ratio in the BALF in HIES, as shown in the current report, is novel, but its significance remains to be elusive. A possibility of inhibition of neutrophil chemotaxis by $\mathrm{CD}^{+}$cells ${ }^{21}$ and switch to the Th2-type secretion profile ${ }^{22}$ that may lead to general IgE overproduction cannot be excluded.

Although lacking mutations in the STAT3 gene, based on the clinical and radiographic findings, the patient is most likely to have the type 1 HIES regardless of the negative family history, as such a possibility has been formerly described. ${ }^{12,23}$ As the Th17 cells are involved in the immunity of the peripheral lung by antimicrobial peptide secretion, looking at the levels of Th17 cells, as well as $\beta$-defensins in the BAL fluid would be of major importance.

This case study not only demonstrates a markedly elevated BALF IgE level in HIES that can be used to support the diagnosis but also raises provocative BALF-related aspects in HIES including a putative link of heightened IgE with the immunologic lesions in HIES, which need to be addressed in further BALFbased studies.

\section{References}

1. Grimbacher B, Holland SM, Gallin JI, et al. Hyper-IgE syndrome with recurrent infections--an autosomal dominant multisystem disorder. N Engl J Med 1999;340:692702.

2. Buckley RH. The hyper-IgE syndrome. Clin Rev Allergy Immunol 2001;20:139-54.

3. Freeman AF, Holland SM. Clinical manifestations, etiology, and pathogenesis of the hyper-IgE syndromes. Pediatr Res 2009;65: 32R-37R.

4. Merrill WW, Out TA. Measurement of immunoglobulins in bronchoalveolar lavage fluid. Report of ERS Task Force: guidelines for measurement of acellular components and recommendations for standardization of bronchoalveolar lavage (BAL). Eur Respir Rev 1999;9:70-75.

5. Technical recommendations and guidelines for bronchoalveolar lavage (BAL). Report of the European Society of Pneumology Task Group. Eur Respir J 1989;2:561-85.

6. Merrill WW, Naegel GP, Olchowski JJ, Reynolds HY. Immunoglobulin G subclass proteins in serum and lavage fluid of normal subjects. Quantitation and comparison with immunoglobulins A and E. Am Rev Respir Dis 1985;131:584-7.

7. Bronchoalveolar lavage constituents in healthy individuals, idiopathic pulmonary fibrosis, and selected comparison groups. The BAL Cooperative Group Steering Committee. Am Rev Respir Dis 1990;141: S169-202.

8. Peebles RS Jr, Liu MC, Lichtenstein LM, Hamilton RG. IgA, IgG and IgM quantification in bronchoalveolar lavage fluids from allergic rhinitics, allergic asthmatics, and normal subjects by monoclonal antibodybased immunoenzymetric assays. J Immunol Methods 1995;179:77-86.

9. Wilson DR, Merrett TG, Varga EM, et al. Increases in allergen-specific IgE in BAL after segmental allergen challenge in atopic asthmatics. Am J Respir Crit Care Med 2002;165:22-6.

10. Minegishi Y. Hyper-IgE syndrome. Curr Opin Immunol 2009;21:487-92.

11. Holland SM, DeLeo FR, Elloumi HZ, et al. STAT3 mutations in the hyper-IgE syndrome. N Engl J Med 2007;357:1608-19.

12. Minegishi Y, Saito M, Tsuchiya S, et al. Dominant-negative mutations in the DNAbinding domain of STAT3 cause hyper-IgE syndrome. Nature 2007;448:1058-62.

13. Hill HR. The syndrome of hyperimmunoglobulinemia E and recurrent infections. Am J Dis Child 1982;136(9):767-71.

14. de Beaucoudrey L, Puel A, Filipe-Santos 0, et al. Mutations in STAT3 and IL12RB1 
impair the development of human IL-17producing T cells. J Exp Med 2008;205: 1543-50.

15. Ma CS, Chew GY, Simpson N, et al. Deficiency of Th17 cells in hyper IgE syndrome due to mutations in STAT3. J Exp Med 2008;205:1551-7.

16. Milner JD, Brenchley JM, Laurence A, et al. Impaired $\mathrm{T}(\mathrm{H}) 17$ cell differentiation in subjects with autosomal dominant hyperIgE syndrome. Nature 2008;452:773-6.

17. Renner ED, Rylaarsdam S, Anover-Sombke $\mathrm{S}$, et al. Novel signal transducer and activator of transcription 3 (STAT3) mutations, reduced $\mathrm{T}(\mathrm{H}) 17$ cell numbers, and variably defective STAT3 phosphorylation in hyper-IgE syndrome. J Allergy Clin Immunol 2008;122:181-7.

18. Schimke LF, Sawalle-Belohradsky J, Roesler J, et al. Diagnostic approach to the hyper-IgE syndromes: immunologic and clinical key findings to differentiate hyperIgE syndromes from atopic dermatitis. J Allergy Clin Immunol 2010;126:611-7.e1.

19. Woellner C, Gertz EM, Schaffer AA, et al. Mutations in STAT3 and diagnostic guidelines for hyper-IgE syndrome. J Allergy Clin Immunol 2010;125:424-432.e8.

20. Minegishi Y, Saito M, Nagasawa M, et al. Molecular explanation for the contradiction between systemic Th17 defect and localized bacterial infection in hyper-IgE syndrome. J Exp Med 2009;206:1291-301.

21. Mazzone A, Girola S, Fossati G, et al. [Job syndrome (hyper-IgE) and hypo-IgA. A rare association of immunodeficiencies]. Recenti Prog Med 1996;87:71-4.

22. Maggi E, Giudizi MG, Biagiotti R, et al. Th2-like CD8+ T cells showing B cell helper function and reduced cytolytic activity in human immunodeficiency virus type 1 infection. J Exp Med 1994;180:48995.

23. Xie L, Hu X, Li Y, et al. Hyper-IgE syndrome with STAT3 mutation: a case report in Mainland China. Clin Dev Immunol 2010; 2010:289873. 